\title{
Preserve patient's confidentiality in primary care
}

\author{
Basem Abbas Al Ubaidi* \\ Consultant Family Physician, North Muharaq Health Centre, Kingdom of Bahrain
}

\begin{abstract}
The law defines the confidentiality as a balance to public interests than a "right" afforded to the person, which contrary conflict with the medical definition. Breaches of patient confidentiality are happened in certain situations (e.g. disclosure to protect others, police cases, notifiable diseases, and patient's fitness to drive).
\end{abstract}

\section{Introduction}

The morality/ethics are an essential need for any profession, particularly medicinal profession. Many of the "Western and Eastern medical ethical schemes" were driven from Hippocratic Oath [1]. "Thomas Percival"(1794) was setting up the "English Constitution for the Doctor" in medical ethics; he provided physicians with fresh standard of conduct [2]. The brand new version of "Constitution of the American Medical Association" was developed in 1980 with influential seven items, while the upgraded version was developed in $2001 \mathrm{using}$ nine significant items [3].

Solving of any medical ethical dilemma should be verified through eight values, but unconditional perfect solutions are not present always. However, it can give an idea of how to grip a particular ethical dilemma, at the same time; it will offer a useful outline for understanding conflicts. The ethical values are (Beneficence ; Non-maleficence; Autonomy; Justice; Dignity; Truthfulness, honesty, and informed consent) $[4,5]$.

The confidentiality element is one of the important foundation stones for supporting "trusted therapeutic relationship" between patients and their doctors. It can be requested by the concerned patients, additionally there is inherent physician's obligation that patient's information is permanently kept confidentially. However, that confidentiality is not outright in all situations. In Bahrain, breach of confidentiality rule was issued in Decree law no. 7, article 126 (1989). Which give permission for giving patient's information at "compulsory legally" required or when there is a significant risk of serious harm to the others if confidentiality is maintained [6].

Confidentiality in the medical setting refers to "the principle of keeping information in state of secured and secret from others" [7]. It is patient's right, and should be maintained even after patient's death [8].

Breaches of confidentiality in routine practice at primary care services don't follow into the standard scenario of disclosure for sensitive clinical information; many may be unintentional or related to lack of knowledge of the relevant legal and professional ethical requirements. A clear understanding of the duty of physicians towards patients' confidentiality and how it is applied in the regular primary care practice is an important competence for all general practitioners (GPs) [9].

Thirds of the calls which had been received by the "Medical
Protection Society" were from primary care physicians who mostly related to the confidential dilemma [10].

\section{Case study}

25 years old, foreigner housemaid female was presented to primary care clinic complaining from delayed in her menses for the last two month, worried that she might be pregnant. A pregnancy test was positive and examination confirmed a pregnancy of 10 weeks. The physician reported the case to the police for illegal pregnancy from her boyfriend.

\section{Case discussion}

The General Medical Council (GMC) has stated that:

Confidentiality is central to trust between doctors and patients. Without assurances about confidentiality, patients may be reluctant to seek medical attention or to give doctors the information to provide the good care [8].

Maintaining confidentiality is part of the "good faith" that exists between doctor and patient [11]. Ignoring patients' confidentiality would lose their trust, and might prevent them from seeking help when needed. Confidentiality will preserve personal dignity, prevents information misuse, and protects patient's autonomous decision, [12] they may not divulge significant information that would support their diagnosis and management [9].

The consequences of breach patient's confidentiality definitely will harm both the individual patient and overall trust in the medical profession [12]. Therefore, physicians should obey the ethical principles by preventing harm and try for benefiting patients.

The physician's breach confidentiality may be acceptable, only when pregnancy scenarios was happened in under age group $(\leq 16$ years) [13] or there was history of sexual abuse/ sexual rape [14].

The rape rule was arranged in Bahrain's Decree-Law No. 15/1976

Correspondence to: Basem Abbas Al Ubaidi, ABFM, MHPEd, Consultant Family Physician, North Muharaq Health Centre, Kingdom of Bahrain, E-mail: bahmed1@health.gov.bh

Received: March 10, 2015; Accepted: April 01, 2015; Published: April 05, 2015 
version of the Penal Code on the show article 344 - that any person has to be punished by imprisonment for a victim not reach the sixteenth under age, or without self-possessed consent of the victim at any adult age, that was unsuitable with our presented case [15].

Any autonomous patient has the right to make verbal/written consent, when possible about who can share patient's facts, even when information is shared in the benefit to the patient/sponsor care. Eventually, any clinician who shares patient's information with others, without patient's consent, does not respect the patient's autonomy and will have behaved in a morally questionable way [10].

However, the duty of confidentiality is not obsolete; and there are many ethical justifications for breaching confidentiality; corresponding in our case study because of harm to the sponsor's contract interest, nonetheless we should take in consideration patient's interest (patient's right). It is legitimate to constrain individual freedom, if that result in harm to others. Nevertheless, personal information should not be disclosed to a third party (e.g. solicitors or police officer) without the patients express their consent.

Breach of patient's confidentiality should be considered in certain situations:

- If there are legal requirements to disclose information (infectious cases).

- If it is asking by various regulatory bodies or by a judge or presiding officer to a court.

- For sharing patient's information within the healthcare team.

- If patient came in an emergency situation.

- If there is request from the patient's insurers.

- To verify patient's medical certificate/report.

- If there is risk of death from serious crime.

- If the patient is victim of neglect or abuse (physical, sexual or emotional abuse).

- To facilitate medical research.

- For education/secondary uses of information that benefit society over time.

- If there is lack of patient mental capacity to give consent (permanent or temporary).

Physician duty of confidentiality should continue even after the patient has died, except in certain circumstances (to write death certificates, when a parent asks for information about the circumstances and causes of a child's death) $[8,10,16]$.

Physicians have a duty to tell the police immediately, when the patient is brought with history or suspicion injuries of gunshot or knife wounds, suicidal attempt, prepared to use weapons, domestic violence and suspicion of the crime/assault/road traffic accidents $[3,8,10,15]$.

In Bahrain, we need more legislative laws on how should physicians maintain and when can they reveal patient's confidentiality? When should physician have legal obligation to report the case to the police department in police cases? When should report to General Directorate of Traffic Office? ; If the patient is diagnosed with a medical condition that could impair fitness to drive $[8,10,16]$.

\section{Key points:}

- Recognizing and maintaining a duty of confidentiality can bring particular challenges in the context of primary care setting.

- Physicians need to be aware of their statutory obligations to disclose information and the limits of this obligation.

- When there is a significant risk of serious harm to others, if information is not shared (the duty to protect or worn may override the duty of confidentiality).

- Medical ethics guidelines that equip primary care physician the necessary competence to solve ethical dilemma.

\section{Recommendation:}

- To formulate a new practical outline "Ethical Curriculum" to Family Practice Residency Programmed (FPRP).

- To set tools on how does tutor in FPRP assist medical ethics teaching process? Check how much do students gain their ethical competencies?

- To have primary care handbook presents an "ethics primer" for family physicians and general practitioners (GPs).

- To have user-friendly, valid, and reliable guidelines with common primary care ethical dilemma discussion.

- To have hotline calls from primary care physician to "Medical Ethical Committee" to discuss confidential dilemma.

- To have more legislative laws on how should physicians maintain and when a physician should reveal the patient confidentiality?

\section{References}

1. http://www.pbs.org/wgbh/nova/body/hippocratic-oath-today.html.

2. http://wikipedia.atpedia.com/en/articles/m/e/d/Medical_ethics.html

3. Percival, Thomas. Medical ethics, 49-57 esp section 8 pg.52.

4. Shanawani H, Lowe KN (2005) Is Greenacres (SNF) the place to be? Virtual Mentor [serial on the Internet]. 2005 [cited 2005 July 24]; 7 (7)

5. Veatch RM (2000) The basics of bioethics. 2nded. Upper Saddle River (NJ): Prentice Hall.

6. http://www.bahrainlaw.net/post1295.html.

7. BMA (1999) Confidentiality and disclosure of health information.

8. General Medical Council (2009) Confidentiality: protecting and providing information 2009.

9. Slowther A (2010) Confidentiality in primary care: ethical and legal considerations InnovAiT 3: 753-759.

10. General Medical Council. Confidentiality (2009a) London: GMC. Accessed via www. gmc-uk.org/guidance/ethical_guidance/confidentiality.asp.

11. O’Neill O (2002) Licence to decieve. Reith lectures.

12. Souhami R, Chalmers S, Collins R, Luker K, Newton J, et al. (2006) Personal data for the public good: using health information in medical research. London: The Academy of Medical Sciences.

13. (1984) Gillickv West Norfolk and Wisbech Area Health Authority. All Engl Law Rep1985: 533-59. [Crossref] 
14. Ablashi DV, Zompetta C, Lease C, Josephs SF, Balachandra N, Komaroff AL, et al. (1991) Human herpesvirus 6 (HHV6) and chronic fatigue syndrome (CFS). Can Dis Wkly Rep 17 (suppl 1E): 33-40. [Crossref]
15. http://ministryofethics.co.uk/index.php?p=6\&q=7.

16. http://www.legalaffairs.gov.bh/LegislationSearchDetails.aspx?id=4069.

Copyright: $\odot 2015 \mathrm{Al}$ Ubaidi BA. This is an open-access article distributed under the terms of the Creative Commons Attribution License, which permits unrestricted use, distribution, and reproduction in any medium, provided the original author and source are credited. 